Berg, B. van den, Grievink, L., Velden, P.G. van der, Yzermans, C.J., Stellato, R.K., Lebret, E., Brunekreef, B.

Risk factors for physical symptoms after a disaster: a longitudinal study.

Psychological Medicine: 2008, 38(4), 499-510

\begin{tabular}{|c|c|}
\hline $\begin{array}{l}\text { Postprint } \\
\text { Version }\end{array}$ & 1.0 \\
\hline Journal website & $\begin{array}{l}\text { http://journals.cambridge.org/action/displayAbstract?fromPage=online\&aid=17 } \\
\text { 75048\& fulltextType=RA\&fileId=S003329170700133X }\end{array}$ \\
\hline Pubmed link & $\begin{array}{l}\text { http://www.ncbi.nlm.nih.gov/sites/entrez?Db=pubmed\&Cmd=ShowDetailView } \\
\text { \&TermToSearch=17892620 }\end{array}$ \\
\hline DOI & $10.1017 / \mathrm{S} 003329170700133 \mathrm{X}$ \\
\hline
\end{tabular}

This is a NIVEL certified Post Print, more info at http://www.nivel.eu

\title{
Risk factors for physical symptoms after a disaster: a longitudinal study
}

\author{
B. VAN DEN BERG ${ }^{\mathrm{A} 1 \mathrm{~A} 2 \mathrm{C} 1}$, L. GRIEVINKA ${ }^{1}$, P. G. VAN DER VELDEN ${ }^{\mathrm{A} 3}$, C. J. YZERMANS ${ }^{\mathrm{A} 4}$, \\ R. K. STELLATO ${ }^{\mathrm{A} 5}$, E. LEBRET ${ }^{\mathrm{A} 1}$ AND B. BRUNEKREEF ${ }^{\mathrm{A} 2 \mathrm{~A} 6}$

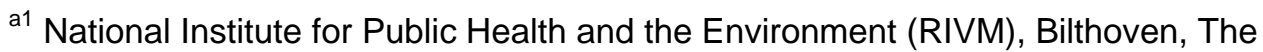 \\ Netherlands \\ a2 Institute for Risk Assessment Sciences (IRAS), Utrecht University, Utrecht, The \\ Netherlands \\ a3 Institute for Psychotrauma (IVP), Zaltbommel, The Netherlands \\ ${ }^{\text {a4 }}$ Netherlands Institute for Health Services Research (NIVEL), Utrecht, The Netherlands \\ ${ }^{a 5}$ Centre for Biostatistics, Utrecht University, Utrecht, The Netherlands \\ a6 Julius Centre, Utrecht University, Utrecht, the Netherlands
}

\section{Abstract}

Background Although symptoms such as fatigue, headache and pain in bones and muscles are common after disasters, risk factors for these symptoms among disaster survivors have rarely been studied. We examined predisposing, precipitating and perpetuating factors for these physical symptoms among survivors of a man-made disaster. In addition, we examined whether risk factors for physical symptoms differ between survivors and controls.

Method Survivors completed a questionnaire 3 weeks ( $\mathrm{n}=1567), 18$ months and 4 years after the disaster. Symptoms and risk factors were measured using validated questionnaires. A comparison group was included at waves 2 and 3 $(\mathrm{n}=821)$. Random coefficient analysis (RCA) was used to study risk factors for symptoms.

Results Female gender [beta $(\beta)=1.0,95 \%$ confidence interval (CI) $0.6-1.4$ ], immigrant status $(\beta=1.0,95 \%$ CI $0.6-1.4)$ and pre-disaster psychological problems $(\beta=0.8,95 \%$ CI $0.1-1.4)$ were predisposing factors for symptoms. Although disaster-related factors were predictors, the relationship between symptoms and disaster-related factors was not very strong and the magnitude of this association was reduced when perpetuating factors were added. Intrusions and avoidance, depression, anxiety and sleeping problems were important perpetuating factors for physical symptoms among survivors and mediated the 
Berg, B. van den, Grievink, L., Velden, P.G. van der, Yzermans, C.J., Stellato, R.K., Lebret, E., Brunekreef, B.

Risk factors for physical symptoms after a disaster: a longitudinal study.

Psychological Medicine: 2008, 38(4), 499-510

association between traumatic stress and physical symptoms. Risk factors for symptoms were comparable between survivors and controls.

Conclusions The results indicate that health-care workers should be alert for physical symptoms among female survivors, immigrant survivors and individuals with a high level of psychological problems both before and after a disaster.

\section{INTRODUCTION}

Life events often precipitate the onset of medically unexplained symptoms (MUS) such as stomach ache, headache and fatigue (Mayou \& Farmer, 2002). For example, several studies have shown that infectious mononucleosis might precipitate chronic fatigue syndrome (Candy et al. 2003; Petersen et al. 2006) and that MUS are associated with stressful events and difficulties prior to onset (Hotopf et al. 1999; Hatcher \& House, 2003). Traumatic events have also been described as precipitating factors for MUS (Escobar et al. 2002; Hasset \& Sigal, 2002; Engel, 2003). Most of the studies that relate traumatic stress to MUS have been performed among Gulf War veterans and have found higher prevalence rates of unexplained symptoms among veterans than among control groups (Unwin et al. 1999; Gray et al. 2002; Thomas et al. 2006). The majority of studies after disasters have focused on mental health problems such as post-traumatic stress disorder (PTSD), depression and anxiety, but a few have also examined physical symptoms comparable to MUS and found elevated levels among survivors (Escobar et al. 1992; Van den Berg et al. 2005a, $b$ ).

Although high levels of symptoms are found among survivors, not every survivor develops symptoms, implying that some survivors are more at risk than others. Risk factors for physical symptoms among survivors of disasters have not often been studied; only a few potential risk factors, such as female gender and high levels of damage, have been consistently identified in disaster studies (Van den Berg et al. 2005a). Risk factors for symptoms that are often referred to as MUS have been studied most frequently among the general population and among war veterans, showing that female gender (Kroenke \& Price, 1993; Wolfe et al. 1998; Hotopf et al. 1999; Feder et al. 2001; Gray et al. 2002; Haug et al. 2004), low socio-economic status (Kroenke \& Price, 1993; Wolfe et al. 1998; Hotopf et al. 1999), living alone (Kroenke \& Price, 1993; Hotopf et al. 1999; Feder et al. 2001) are risk factors for these symptoms. In addition to these predisposing factors, co-morbid psychological problems such as PTSD and anxiety have been described as perpetuating factors that maintain and exacerbate symptoms (Kroenke \& Price, 1993; Wolfe et al. 1998; Feder et al. 2001; Haug et al. 2004; Hotopf et al. 2004). Several studies among war veterans have indicated that these psychological problems, especially PTSD, mediate the relationship between traumatic exposure and physical symptoms (Schnurr \& Green, 2003; Norris et al. 2005).

Insight into factors that predict symptoms among survivors of disasters is useful to better understand the relationship between traumatic exposure and physical symptoms. In addition, information about risk factors could be important for health-care workers and policy makers as it facilitates both the detection of those at risk and the implementation of preventive interventions to reduce risk. It is, however, not known whether the risk factors that have been found in studies among the general population and among war veterans are similar for survivors of disasters. In addition, precipitating factors such as destroyed house and peritraumatic dissociation, which have been described as potential risk factors for symptoms (Engel, 2003), have not been examined in previous studies. In the present longitudinal study, we addressed two research questions. First, what are the predisposing (e.g. gender), precipitating (e.g. house destroyed) and perpetuating (e.g. anxiety) factors for physical symptoms (e.g. headache, fatigue) among survivors of a man-made disaster? Second, are risk factors for symptoms comparable between survivors and non-traumatized controls? 
Berg, B. van den, Grievink, L., Velden, P.G. van der, Yzermans, C.J., Stellato, R.K., Lebret, E., Brunekreef, B.

Risk factors for physical symptoms after a disaster: a longitudinal study.

Psychological Medicine: 2008, 38(4), 499-510

\section{METHOD}

\section{Study design and participants}

On 13 May 2000 a fireworks depot exploded in a residential area in the city of Enschede, The Netherlands. As a result of the explosion and subsequent fire, 23 people died, more than 900 were injured and about 1200 were forced to relocate because their houses were severely damaged or destroyed. The Dutch government declared this a national disaster and started a longitudinal study into the health consequences of the disaster.

Details of the study population and procedures have been described elsewhere (Roorda et al. 2004; Van den Berg et al. 2005b; Van Kamp et al. 2006; Grievink et al. 2007).

In summary, the first wave (T1) of this study was performed 3 weeks post-disaster. Residents of the affected area were invited to participate in the health survey by means of letters and announcements in the local media. In total, 1567 affected residents (estimated response $\approx 30 \%$ ) completed a questionnaire at $\mathrm{T} 1$.

Approximately 18 months post-disaster, from November 2001 to January 2002, the second wave (T2) was performed. All T1 participants who had given informed consent for future contact and who were not lost to follow-up due to death or emigration received an announcement letter. In addition, a sample of 1600 residents was drawn from the registry office in the city of Tilburg, The Netherlands, to serve as a control group. The control group was stratified according to sex, age and country of origin to make it comparable to the survivors who participated at T1.

To stimulate participation, survivors and controls were telephoned at home after the announcement letter was sent. If a respondent agreed to participate, a questionnaire was sent to their home address in their preferred language (Dutch, German, English or Turkish). Interpreters were available at a community centre to assist in completing the questionnaires. At T2, 1116 survivors out of 1551 eligible survivors (response $72 \%$ ) and 821 controls out of 1600 eligible controls (response 52\%) completed a questionnaire.

Nearly 4 years post-disaster (January-March 2004), a third survey (T3) was performed. Except for participants who were lost to follow-up, all survivors of $\mathrm{T} 1$ and all controls from T2 who had given written informed consent for future contact were invited to participate. Participation was encouraged by means of home visits and telephone calls. As at wave 2, interpreters were available at community centres to assist in completing the questionnaires. At T3, 51 survivors and 28 controls were lost to follow-up. In total, 995 out of 1516 eligible survivors (response 66\%) and 589 out of 793 eligible controls (response $74 \%$ ) completed a questionnaire at $\mathrm{T} 3$.

\section{Measures}

The questionnaires were comparable for survivors and controls but disaster-related questions were not included in the control questionnaire.

\section{Physical symptoms}

At T1, symptoms were measured by a 13-item questionnaire about subjective health complaints (VOEG-13; Van Sonsbeek, 1990), a validated scale that has often been used for studies in the Dutch population. The items asked respondents whether they regularly had symptoms such as stomach ache, fatigue, headache and backache. At T2 and T3, this questionnaire was extended to 21 different symptoms (VOEG-21). In this study, the extended scale measured at T2 and T3 was used as the outcome variable (Van den Berg et al. 2005b).

\section{Predisposing factors}

The following demographic and lifestyle characteristics were measured: sex, age, educational level, occupational status (having a paid job), cigarette smoking and immigrant 
Berg, B. van den, Grievink, L., Velden, P.G. van der, Yzermans, C.J., Stellato, R.K., Lebret, E., Brunekreef, B.

Risk factors for physical symptoms after a disaster: a longitudinal study.

Psychological Medicine: 2008, 38(4), 499-510

status (first and second generation, mainly of Turkish origin). For survivors, self-reported pre-disaster psychological and relational problems reported at T1 were included.

\section{Precipitating factors}

Several experiences during or soon after the disaster were measured at $\mathrm{T} 1$ : relocation due to a severely damaged or destroyed house; the loss of loved ones (family, colleagues, friends); and injury requiring medical treatment. In addition, several questions asked about what survivors had seen, heard and felt during the disaster. A scale was made for the 29 items; survivors with 18 or more experiences (80th percentile) were defined as having a high disaster exposure. Finally, the extent to which survivors had experienced peritraumatic dissociation during or immediately after the disaster was measured by the Peritraumatic Dissociative Experiences Questionnaire. The total score of this scale ranges from 10 to 50 . Survivors with a score higher than 35 (80th percentile) were defined as having high levels of peritraumatic dissociation (Marmar et al. 1997).

\section{Perpetuating factors}

Several mental health problems were measured at all waves of the health survey. For the survivors, the impact of event scale (IES) was used to measure intrusions and avoidance reactions, which serve as an indication for a clinical level of PTSD (Horowitz et al. 1979; Van der Ploeg et al. 2004). Survivors with an overall score above 25 were defined as having a high level of intrusions and avoidance reactions. Among survivors and controls, feelings of depression, anxiety and hostility were measured by the Dutch version of the 90 -item Symptom Checklist (SCL-90; Derogatis et al. 1973). We dichotomized the scales into high (80th percentile) versus low scores, according to established references for the healthy Dutch population (Arrindell \& Ettema, 1986). Sleeping difficulties were measured by the Groninger Sleep Quality Scale; the scale ranges from 0 to 10, respondents with a score above 4 were defined as having severe sleeping difficulties (Meijman et al. 1985).

\section{Statistical analysis}

For both survivors and controls, all wave completers had different characteristics compared with non-respondents at follow-up (Van den Berg et al. 2007). Because deleting the incomplete cases might lead to biased results, we corrected for this selective response by means of multiple imputation (MI) (Rubin, 1987). This statistical method makes use of the intercorrelations of variables from the non-missing data to estimate plausible values for the data that are missing. MI is considered a better method for dealing with missing data than other more commonly used methods such as mean imputation (Rubin, 1987; Schafer \& Graham, 2002). The outcome of interest (21 physical symptoms) and all risk factors, measured at the different waves, were included in the MI model. In addition, variables that correlated highly with the potential risk factors and with the symptom scale were selected because this increases the power of the multiple imputation model (Schafer \& Graham, 2002). Table 1 presents the additional variables included in the MI model. We did not dichotomize any of the continuous variables entered in the model. We applied an adapted version of predictive mean matching using an SAS (SAS Institute Inc., Cary, NC, USA) macro that makes partial use of the SAS version 9.1 MI procedure (Lazzeroni et al. 1990). Five datasets were generated in which the non-missing data are the same and the values imputed for the missing data vary between datasets. We analysed these datasets separately and combined the results using the MIANALYZE procedure in SAS, which produces valid confidence intervals by taking the uncertainty due to missing data into account.

\section{[TABLE 1]}

Pearson correlation analysis was performed to investigate the relationships between the precipitating factors, perpetuating factors and reported symptoms. 
Berg, B. van den, Grievink, L., Velden, P.G. van der, Yzermans, C.J., Stellato, R.K., Lebret, E., Brunekreef, B.

Risk factors for physical symptoms after a disaster: a longitudinal study.

Psychological Medicine: 2008, 38(4), 499-510

Because the survey data were collected longitudinally, with three measurements times for the survivors, random coefficient analysis (RCA) was used to examine risk factors for symptoms among survivors. RCA takes into account the correlation between repeated measurements on a subject, and both subject-level (e.g. gender) and time-varying (e.g. depression) variables can be included simultaneously in the model. In the current analyses, random intercept models were used, which means that each subject has their own intercept (Singer \& Willett, 2003). Before performing RCA, multiple regression analyses were performed for symptoms at T2 and T3 separately to confirm that the direction and strength of associations between the risk factors and symptoms were similar for the two waves. RCA proceeded in four steps. In the first model we studied whether predisposing factors predicted symptoms at T2 and T3. In the second model, we added the precipitating factors to the model. In the third model, perpetuating factors at an earlier point in time $(\mathrm{T}-1)$ than the reported symptoms were added. In the fourth model, concurrent perpetuating factors were added.

As disaster-related factors were not measured in the control survey, considerably fewer risk factors were examined for the controls. The control group was included only at T2 and T3, and therefore risk factors could only be studied for symptoms reported at T3. For these reasons, multiple regression models were used to compare risk factors between survivors and controls. The survivor and control groups were analysed separately to determine whether the direction and strength of associations between the risk factors and symptoms reported at T3 were similar. These stratified analyses revealed that risk factors for symptoms among survivors and controls were comparable. The two groups were thus analysed in one model, with an indicator for 'disaster exposure' (survivors versus controls). Although the confidence intervals were overlapping, some factors appeared to differ between survivors and controls. For these factors, interaction effects were tested in the combined model.

Because respondents with chronic diseases could have symptoms that are associated with their disease, all results were adjusted for concurrent chronic diseases such as diabetes, cancer, asthma and chronic stomach disorders.

\section{RESULTS}

\section{Correlation analysis}

Table 2 shows the Pearson correlation coefficients among precipitating factors, perpetuating factors and physical symptoms reported by survivors. The correlation between physical symptoms at T1, T2 and T3 and the precipitating factors was low $(0.05<\mathrm{r}<0.19)$. There was a relatively strong correlation between psychological problems and physical symptoms $(0.36<r<0.70)$. The correlation between the physical symptoms reported at the different points in time was also strong $(0.57<\mathrm{r}<0.90)$. The correlation coefficients were comparable for the control group (data not shown).

\section{[TABLE 2]}

\section{Risk factors for symptoms reported by survivors}

Table 3 presents the results of the RCA for symptoms reported by survivors at T2 and T3. In model 1, female gender, immigrant status, pre-disaster psychological problems and predisaster relational problems were the most important risk factors for self-reported symptoms. For example, female survivors reported on average 1.2 symptoms more on the 21 -item symptoms scale than male survivors $(\beta=1.2,95 \%$ CI $0.8-1.6)$. These associations remained when precipitating factors were added to the regression model. Model 2 shows that disasterrelated factors were associated with a higher mean number of symptoms among survivors. For example, survivors who had lost a loved one reported on average one symptom more than those who had not ( $\beta=1.0,95 \%$ CI $0.2-1.8)$. These associations diminished after entering perpetuating factors into the model (models 3 and 4 ). With the exception of gender, 
Berg, B. van den, Grievink, L., Velden, P.G. van der, Yzermans, C.J., Stellato, R.K., Lebret, E., Brunekreef, B.

Risk factors for physical symptoms after a disaster: a longitudinal study.

Psychological Medicine: 2008, 38(4), 499-510

the associations between predisposing factors and symptoms also diminished after adding perpetuating factors; the effects of low educational level and pre-disaster relational problems disappeared in model 3 ( $\beta=0.3,95 \% \mathrm{CI}-0.1$ to 0.7 and $\beta=0.9,95 \% \mathrm{CI}-0.1$ to 2.0 respectively). In model 3 , all distress reactions measured at an earlier time point, with the exception of feelings of hostility ( $\beta=0.2,95 \% \mathrm{CI}-0.3$ to 0.6 ), were positively associated with a higher mean number of symptoms. This relationship diminished when concurrent perpetuating factors were added (model 4), indicating stronger associations between concurrent distress and symptoms. The full model showed a strong association between concurrent psychological problems and physical symptoms. In addition, female gender, immigrant status and pre-disaster psychological problems were important risk factors for self-reported symptoms at T2 and T3 in model 4.

\section{[TABLE 3]}

\section{Risk factors for symptoms reported by survivors and controls}

Table 4 shows the results of the multiple regression analysis in which potential risk factors for symptoms among survivors and controls were analysed together. When predisposing factors were controlled for, survivors of the disaster reported on average 1.1 symptoms more $(\beta=1.1,95 \%$ CI $0.7-1.4)$ at T3 than control subjects (model 1$)$. When psychological problems were entered in the model (model 2), the associations between predisposing factors and symptoms diminished and the effect of disaster exposure disappeared (survivor of the fireworks disaster $\beta=-0.1,95 \%$ CI -0.4 to 0.3 ). In model 2 , physical symptoms and different psychological problems measured at an earlier point in time were statistically significantly related to self-reported symptoms. These effects diminished or disappeared when concurrent psychological problems were added in model 3. Model 4 showed that among survivors and controls, female gender, no paid job, immigrant status, physical symptoms at an earlier point in time, as well as concurrent feelings of depression, anxiety and sleeping problems, were associated with physical symptoms at $\mathrm{T} 3$. There was an interaction effect between disaster survivor and concurrent sleeping problems $(\beta=0.8,95 \%$ CI $0.1-1.6)$, indicating that survivors with a high level of sleeping problems at $\mathrm{T} 3$ reported on average nearly one symptom more at $\mathrm{T} 3$ than did controls with a high level of sleeping problems. The associations between the other risk factors and symptoms were similar between survivors and controls.

\section{[TABLE 4]}

\section{Discussion}

In the present longitudinal study, we examined predisposing, precipitating and perpetuating factors for physical symptoms reported by survivors of a fireworks disaster. Female gender, immigrant status and pre-disaster psychological problems were the most important predisposing factors for symptoms reported 18 months and 4 years post-disaster. In addition, physical symptoms, intrusions and avoidance, depression and anxiety measured at an earlier point in time as well as concurrent intrusions and avoidance, depression, anxiety and sleeping problems were associated with a higher mean number of symptoms among survivors. The effect of precipitating factors, such as having one's house destroyed, was mediated by the perpetuating factors. Risk factors were comparable between survivors and non-traumatized controls.

In line with previous studies, female gender and pre-disaster psychological problems were important predisposing factors for symptoms (Kroenke \& Price, 1993; Feder et al. 2001). In the present study, immigrant status was also an important predisposing factor for physical symptoms. Immigrant status has less often been studied in relation to physical symptoms, and little is known about the relationship between ethnicity and physical symptoms. Despite 
Berg, B. van den, Grievink, L., Velden, P.G. van der, Yzermans, C.J., Stellato, R.K., Lebret, E., Brunekreef, B.

Risk factors for physical symptoms after a disaster: a longitudinal study.

Psychological Medicine: 2008, 38(4), 499-510

this, it can be hypothesized that non-western immigrants are more likely to express feelings of distress in a somatic rather than in a psychological way. Indeed, Terheggen et al. (2001) showed that Tibetan refugees were more likely to have a high score on somatically phrased items than on items that were phrased in a psychological way.

The analyses showed that the correlation between disaster-related factors, such as house destroyed and loss of a loved one, and self-reported physical symptoms at T2 and T3 was low. This finding differs from other disaster studies, in which it was found that high levels of damage due to the disaster was a risk factor for physical symptoms (Van den Berg et al. 2005a). Although disaster-related factors were related to physical symptoms in our regression models, this association diminished after adding distress reactions such as feelings of depression and anxiety to the model. Previous studies did not adjust for distress after the disaster. In addition, the association between peritraumatic dissociation, which has been proposed as a potential risk factor for physical symptoms and other distress reactions, also diminished after adjusting for psychological distress (Engel, 2003; Van der Velden et al. 2006).

These results support the hypothesis that distress following traumatic exposure mediates the association between exposure and physical health problems (Schnurr \& Green, 2003; Norris et al. 2005). Schnurr \& Green (2003) proposed PTSD as the primary pathway through which trauma leads to physical health problems. In our study, the associations between depression and anxiety and symptoms were as strong as, or even stronger than, the association between symptoms of PTSD and physical symptoms. This suggests that PTSD might not be the primary pathway, but that other post-disaster distress reactions also mediate the relationship between exposure and physical symptoms.

High correlations were found among the different perpetuating factors and between the perpetuating factors and physical symptoms. High correlations between factors might result in unstable estimates and high standard errors. Collinearity diagnostics indicated that collinearity was not a problem in our regression models. However, the strong correlations do indicate a high level of co-morbidity among the disaster survivors. Previous studies among the general population and war veterans also found high levels of co-morbidity between depression, anxiety and PTSD and MUS (Kroenke \& Price, 1993; Feder et al. 2001). In addition, we found that about $65 \%$ of survivors with 10 to 14 symptoms and about $85 \%$ of survivors with 15 or more symptoms on the symptom scale reported high levels of depression and anxiety, suggesting that symptoms are related to, but not fully dependent on, psychological problems (Van den Berg et al. 2005a).

Although the results show a high level of co-morbidity between physical symptoms and psychological problems, the direction of the association is not clear. Psychological problems and sleeping problems are perpetuating factors in our model, but it is likely that physical symptoms also perpetuate sleeping problems and feelings of anxiety and depression. Therefore, health-care workers should be alert not only for physical symptoms among patients with sleeping problems, feelings of anxiety or depression but also for sleeping problems and psychological problems among patients with physical symptoms.

In the analyses comparing survivors and controls, the effect of disaster exposure disappeared after adding perpetuating factors to the model. This result supports the hypothesis that physical symptoms are more strongly related to distress than to the traumatic exposure and confirms previous findings that psychological problems are important risk factors for physical symptoms (Kroenke \& Price, 1993; Wolfe et al. 1998; Feder et al. 2001; Haug et al. 2004; Hotopf et al. 2004).

Risk factors for physical symptoms among survivors were also comparable with the risk factors for symptoms that are referred to as MUS among the general population and war veterans and were similar between survivors and controls (Kroenke \& Price, 1993; Wolfe et al. 1998; Hotopf et al. 1999; Feder et al. 2001; Gray et al. 2002; Haug et al. 2004). This indicates that risk factors for symptoms among disaster survivors are similar to risk factors for physical symptoms among other populations. 
Berg, B. van den, Grievink, L., Velden, P.G. van der, Yzermans, C.J., Stellato, R.K., Lebret, E., Brunekreef, B.

Risk factors for physical symptoms after a disaster: a longitudinal study.

Psychological Medicine: 2008, 38(4), 499-510

Some of the risk factors, such as pre-disaster psychological problems and pre-disaster relational problems, were not available for the controls and could not be studied for survivors and controls in the combined regression model. However, previous studies in the general population have shown that previous psychological problems and social problems are risk factors for physical symptoms, and therefore it is likely that these factors were also predisposing factors for symptoms among the controls (Katon \& Walker, 1998; Aggarwal et al. 2006).

In the present study we examined risk factors for symptoms reported in a 21-item symptom scale. Although studying a high level of symptoms might provide information that is more useful for clinicians, we did not dichotomize the symptoms as there is no generally accepted convention on a cut-off point or a case definition for symptoms (Hiller et al. 2006). In addition, the distribution of symptoms among survivors did not show a clear cut-off point and dichotomizing symptoms into a high and a low level of symptoms would have resulted in a loss of information. As studies have shown that different functional somatic syndromes (that exist of clusters of symptoms) share common risk factors (Aggarwal et al. 2006), it is unlikely that clusters of symptoms among survivors of the fireworks disaster would have different risk factors.

This study has several strengths. First, information about disaster exposure was obtained 3 weeks post-disaster. Delay in data collection may introduce recall bias and important data may be lost forever. Second, we included a control group at T2 and T3, which gave us the opportunity to compare risk factors for symptoms between survivors and controls. Third, in contrast to most of the previous disaster studies that examined risk factors for physical symptoms, we were able to longitudinally analyse the risk factors, showing that, in addition to concurrent distress, distress reactions reported at an earlier point in time were risk factors for symptoms. This information is useful for screening of people at risk for developing symptoms.

Despite these strengths, some potential limitations should be considered. First, because only $30 \%$ of all affected residents participated in the first health survey, selective response and possible bias are of concern in this study. Shortly after the disaster, all affected adult residents were registered at an information and advice centre (IAC) that was established to supply information to survivors and to coordinate their needs. To detect possible selective participation, the database of the IAC was used to compare demographic characteristics of participants with those of the non-participants. Participation was somewhat selective: women, those living with a partner, those aged 45-64 years and immigrants were more likely to participate. However, further analyses of MI indicated that the prevalence estimates of health problems were barely affected by this selective participation (Grievink et al. 2006). In this database, it was also registered whether or not survivors had to relocate because of serious damage to their house. It was confirmed that participants and non-participants in the health survey did not differ with regard to relocation. Despite this, no information on emotional distress or loss of a loved one was registered in the IAC database. It is therefore unclear whether or not survivors with high levels of emotional distress were less likely to participate in the health survey, resulting in biased prevalence estimates of (psychological) health problems among survivors in the health survey. In addition, no information on personal injuries due to the disaster was available from this database. It is, however, possible that those with personal injuries were less able to participate in the health survey, which was completed at an air force base outside the city of Enschede 3 weeks post-disaster.

In addition, there was some selective response at T2 and T3. Among survivors, all wave completers $(\mathrm{n}=815)$ were more likely to be female, middle-aged, highly educated, native Dutch and to have a paid job than survivors who did not participate at all three surveys. Among the controls, those who participated at both surveys $(\mathrm{n}=793)$ were younger, more highly educated, and more likely to have a paid job than the controls who participated only at the first survey. Analyses of MI showed that this selective response hardly affected the prevalence estimates of health problems among survivors (Van den Berg et al. 2007). 
Berg, B. van den, Grievink, L., Velden, P.G. van der, Yzermans, C.J., Stellato, R.K., Lebret, E., Brunekreef, B.

Risk factors for physical symptoms after a disaster: a longitudinal study.

Psychological Medicine: 2008, 38(4), 499-510

Despite these results, we used MI in the present study to correct for selective response and to increase the power of the regression models. We believe that the MI model was adequate for predicting the missing data because it included variables related to missingness (e.g. gender, age, education). We also expected that the inclusion of additional variables in the imputation model (Table 1) that were strongly correlated with the variables of interest (containing missing values) increased the power of the MI model (Schafer \& Graham, 2002). We have performed the RCA both with and without imputing the missing data for nonrespondents. The results of the RCA without MI were similar to the results of the RCA with imputed values. This is in line with the findings that selective response hardly affected the prevalence estimates of health problems among survivors (Grievink et al. 2006; Van den Berg et al. 2007).

A second limitation of the current study is that symptoms were measured by means of a questionnaire. Symptoms reported in a questionnaires might be an overestimation of symptoms that are reported to the general practitioner (GP) because not all individuals seek medical care for their symptoms (Green et al. 2001). In addition, because only examination by a GP can exclude medical disorders, it is not known whether the symptoms reported by survivors and controls are medically unexplained (MUS) or can be explained by a medical disorder. However, in a recent study we found that symptoms reported by the survivors showed features similar to those of MUS, such as associations with functional impairment and high levels of psychological problems (Van den Berg et al. 2005b). In addition, when presented to the GP, the majority of symptoms (56-91\%) reported by survivors could not be explained by a medical disorder and were labelled as MUS (Donker et al. 2002; B. van den Berg, unpublished manuscript).

Third, pre-disaster questionnaire data were not available for the population affected by the fireworks disaster. At T2 and T3 we included a stratified controls group to compare health problems among survivors with those of unaffected controls. Compared to this control group, the survivors of the fireworks disaster reported significantly more psychological problems and physical symptoms (Van den Berg et al. 2005b; Grievink et al. 2007). Predisaster GP data were also available for the survivors of the fireworks disaster, and analyses of the GP data showed a considerable increase in health problems among survivors after the disaster compared to pre-disaster (Yzermans et al. 2005).

To our knowledge, this is the first study that has thoroughly studied risk factors for physical symptoms among survivors of a disaster. Female gender, immigrant status and pre-disaster psychological problems were important predisposing factors for symptoms. Psychological problems such as PTSD and depression were important perpetuating factors for symptoms and mediated the relationship between traumatic exposure and symptoms that are often referred to as MUS. The risk factors were similar between survivors and controls and were comparable with risk factors that have been found in studies among the general population and war veterans. These results indicate that health-care workers should be alert for physical symptoms especially among females, immigrants and individuals with pre-disaster psychological problems. The high level of co-morbidity between psychological problems and physical symptoms that was found in this study also suggests that health-care workers might prevent the development and perpetuation of physical symptoms by treating these psychological problems.

\section{ACKNOWLEDGEMENTS}

This longitudinal study was part of the Enschede Firework Disaster Health Monitoring Project (GGVE) and was performed under the authority of and funded by the Ministry of Health, Welfare and Sports in The Netherlands. We thank Dr S. van Buuren and G. Jacobusse (TNO Quality of Life) for their statistical advice and Dr H. Boshuizen (RIVM) for the use of her SAS macro for predictive mean matching. 
Berg, B. van den, Grievink, L., Velden, P.G. van der, Yzermans, C.J., Stellato, R.K., Lebret, E., Brunekreef, B.

Risk factors for physical symptoms after a disaster: a longitudinal study.

Psychological Medicine: 2008, 38(4), 499-510

\section{TABLES}

Table 1. Variables used in the multiple imputation model, in addition to the 21-item symptom scale and the selected potential risk factors ${ }^{\mathrm{a}}$

\begin{tabular}{|c|c|c|}
\hline Description of variable & $\begin{array}{l}\text { Survivors } \\
\text { Available } \\
\text { at waves }\end{array}$ & $\begin{array}{l}\text { Controls } \\
\text { Available } \\
\text { at waves }\end{array}$ \\
\hline 13-item VOEG scale (Van Sonsbeek, 1990) & T1 & N.A. \\
\hline Optimism subscale (Scheier et al. 1994) & $\mathrm{T} 2, \mathrm{~T} 3$ & $\mathrm{~T} 2, \mathrm{~T} 3$ \\
\hline Social support scale (Van Sonderen, 1993) & $\mathrm{T} 2, \mathrm{~T} 3$ & $\mathrm{~T} 2, \mathrm{~T} 3$ \\
\hline Distrust subscale (Mooren \& Kleber, 2001) & $\mathrm{T} 2, \mathrm{~T} 3$ & N.A. \\
\hline $\begin{array}{l}\text { Nine subscales of the RAND-36 (Van der Zee \& Sanderman, 1993; } \\
\text { Aaronson et al. 1998)c }\end{array}$ & $\mathrm{T} 1, \mathrm{~T} 2, \mathrm{~T} 3$ & \\
\hline $\begin{array}{l}\text { SCL-90: somatization, obsessive-compulsive, sleeping problems, phobic } \\
\text { anxiety and interpersonal sensitivity subscale (Derogatis et al. 1973; } \\
\text { Arrindell \& Ettema, 1986) }\end{array}$ & $\mathrm{T} 1, \mathrm{~T} 2, \mathrm{~T} 3$ & $\mathrm{~T} 2, \mathrm{~T} 3$ \\
\hline $\begin{array}{l}\text { State Anxiety Inventory : state anger and anger expression subscale } \\
\text { (Van der Ploeg et al. 1982) }\end{array}$ & $\mathrm{T} 2$ & N.A. \\
\hline Five items of the IES (Horowitz et al. 1979; Van der Ploeg et al. 2004) & $\mathrm{T} 1, \mathrm{~T} 2, \mathrm{~T} 3$ & N.A. \\
\hline $\begin{array}{l}\text { Single items of SCL-90 subscales: depression (four items), anxiety } \\
\text { (three items), hostility (two items) (Derogatis et al. 1973; Arrindell \& } \\
\text { Ettema, 1986) }\end{array}$ & $\mathrm{T} 1, \mathrm{~T} 2, \mathrm{~T} 3$ & $\mathrm{~T} 2, \mathrm{~T} 3$ \\
\hline
\end{tabular}

VOEG, Questionnaire into Subjective Health Complaints [Vragenlijst voor Onderzoek naar de Ervaren Gezondheid]; RAND-36, RAND 36-Item Health Survey; SCL-90, 90-item Symptom Checklist; IES, Impact of Event Scale; N.A., not available.

${ }^{a}$ Additional scales and items correlated $r>0.50$ with the 21 -item symptom scale and the selected potential risk factors.

b To be included in the random coefficient analyses (RCA), scales had to be available at all three waves of the health survey. ${ }^{c}$ The subscales Physical functioning, Energy/fatigue and Mental well-being were not measured at T1.

${ }^{d}$ The IES was missing when two or more items were missing and the SCL-90 subscales were missing when three or more items were missing. As the individual items were less often missing and highly correlated with the subscales, these items were included in the imputation model. 
Table 2. Pearson correlation coefficients among precipitating factors and perpetuating factors selected for random coefficients analyses for physical symptoms reported by survivors $(n=1567)$ at $T 2$ and $T 3^{\mathrm{a}}$

Questionnaire into Subjective Health Complaints.

a Continuous variables were used in the correlation analysis, except for house destroyed, lost a loved one and injury self. 
Berg, B. van den, Grievink, L., Velden, P.G. van der, Yzermans, C.J., Stellato, R.K., Lebret, E., Brunekreef, B.

Risk factors for physical symptoms after a disaster: a longitudinal study.

Psychological Medicine: 2008, 38(4), 499-510

Table 3. Associations between predisposing, precipitating and perpetuating factors and physical symptoms among survivors $(n=1567)$ reported at $T 2$ and $T 3$ of the longitudinal health survey ${ }^{\mathrm{a}}$

\begin{tabular}{|c|c|c|c|c|c|c|c|c|}
\hline & \multicolumn{2}{|c|}{$\begin{array}{l}\text { Model } 1 \\
\text { Predisposing } \\
\text { factors only }\end{array}$} & \multicolumn{2}{|c|}{$\begin{array}{l}\text { Model } 2 \\
\text { Model } 1+ \\
\text { precipitating } \\
\text { factors }\end{array}$} & \multicolumn{2}{|c|}{$\begin{array}{l}\text { Model } 3 \\
\text { Model 2+ } \\
\text { perpetuating } \\
\text { factors T-1 }\end{array}$} & \multicolumn{2}{|c|}{$\begin{array}{l}\text { Model } 4 \\
\text { Model } 3+\text { concurrent } \\
\text { perpetuating factors }\end{array}$} \\
\hline & $\beta$ & $95 \% \mathrm{CI}$ & $\beta$ & $95 \% \mathrm{CI}$ & $\beta$ & $95 \% \mathrm{CI}$ & $\beta$ & $95 \% \mathrm{CI}$ \\
\hline Intercept & 6.3 & $5.5-7.0$ & 6.6 & $5.7-7.4$ & 3.6 & $2.8-4.4$ & 1.8 & $1.1-2.5$ \\
\hline Female & 1.2 & $0.8-1.6$ & 1.1 & $0.7-1.6$ & 0.8 & $0.4-1.2$ & 1.0 & $0.6-1.4$ \\
\hline Age & 0.01 & -0.004 to 0.03 & 0.02 & $0.001-0.03$ & 0.01 & -0.002 to 0.03 & 0.02 & $0.004-0.03$ \\
\hline Low educational level & 0.7 & $0.2-1.2$ & 0.5 & $0.1-1.0$ & 0.3 & -0.1 to 0.7 & 0.1 & -0.3 to 0.5 \\
\hline Unemployed T-1 & 0.9 & $0.4-1.3$ & 0.8 & $0.3-1.2$ & 0.7 & $0.3-1.1$ & 0.3 & -0.1 to 0.7 \\
\hline Immigrant & 3.5 & $3.0-4.0$ & 2.9 & $2.4-3.4$ & 2.0 & $1.6-2.4$ & 1.0 & $0.6-1.4$ \\
\hline Smoker T-1 & 0.9 & $0.3-1.4$ & 0.8 & $0.2-1.3$ & 0.6 & $0.1-1.0$ & 0.5 & $0.1-0.8$ \\
\hline Pre-disaster psychological problems & 2.0 & $1.1-3.0$ & 1.8 & $0.9-2.7$ & 1.1 & $0.3-1.8$ & 0.8 & $0.1-1.4$ \\
\hline Pre-disaster relational problems & 1.8 & $0.4-3.2$ & 1.4 & $0.1-2.8$ & 0.9 & -0.1 to 2.0 & 0.4 & -0.4 to 1.2 \\
\hline House destroyed & & & 1.0 & $0.5-1.5$ & 0.5 & $0.1-0.8$ & 0.2 & -0.2 to 0.5 \\
\hline Lost a loved one & & & 1.0 & $0.2-1.8$ & 0.5 & -0.2 to 1.2 & 0.4 & -0.3 to 1.0 \\
\hline Injury self & & & 1.2 & $0.5-1.9$ & 0.8 & $0.2-1.4$ & 0.6 & -0.001 to 1.2 \\
\hline High disaster exposure & & & 1.1 & $0.5-1.6$ & 0.5 & $0.1-1.0$ & 0.2 & -0.2 to 0.6 \\
\hline Peritraumatic dissociation & & & 1.7 & $1.2-2.1$ & 0.7 & $0.3-1.1$ & 0.3 & $0.1-0.7$ \\
\hline Physical symptoms T- $1^{\mathrm{b}}$ & & & & & 1.4 & $1.0-1.9$ & 1.0 & $0.6-1.5$ \\
\hline Intrusions and avoidance $\mathrm{T}-1$ & & & & & 0.8 & $0.5-1.1$ & 0.5 & $0.2-0.8$ \\
\hline Depressive feelings T-1 & & & & & 1.0 & $0.5-1.5$ & 0.5 & $0.02-1.0$ \\
\hline Feelings of anxiety $\mathrm{T}-1$ & & & & & 0.9 & $0.5-1.4$ & 0.5 & $0.1-1.0$ \\
\hline Feelings of hostility T-1 & & & & & 0.2 & -0.3 to 0.6 & -0.1 & -0.5 to 0.4 \\
\hline Sleeping problems T-1 & & & & & 0.6 & $0.2-1.0$ & 0.3 & $0.04-0.7$ \\
\hline Intrusions and avoidance (concurrent) & & & & & & & 0.8 & $0.3-1.3$ \\
\hline Depressive feelings (concurrent) & & & & & & & 1.5 & $1.1-2.0$ \\
\hline Feelings of anxiety (concurrent) & & & & & & & 1.3 & $0.9-1.7$ \\
\hline Feelings of hostility (concurrent) & & & & & & & 0.4 & -0.002 to 0.9 \\
\hline Sleeping problems (concurrent) & & & & & & & 1.6 & $1.1-2.0$ \\
\hline
\end{tabular}

CI, Confidence interval.

a The regression coefficient $(\beta)$ is adjusted for concurrent chronic diseases and represents the increase or decrease of symptoms reported on the 21-item symptom scale for survivors with that characteristic. Symptoms are: listlessness, fatigue, forgetfulness, ringing in the ears, pain in the chest and the region of the heart, lump in the throat, stomach ache, pain in the bones and muscles, nausea, dizziness, pain in the neck and shoulders, cold fingers, hand and feet, excessive sweating, pain in the back, headache, deafness, tight feeling in the chest, tingling in arms and chest, poor vision, shortness of breath, fainting.

b13-item symptom scale (VOEG-13). 
Berg, B. van den, Grievink, L., Velden, P.G. van der, Yzermans, C.J., Stellato, R.K., Lebret, E., Brunekreef, B.

Risk factors for physical symptoms after a disaster: a longitudinal study.

Psychological Medicine: 2008, 38(4), 499-510

Table 4. Associations between possible risk factors and physical symptoms among survivors $(n=1567)$ and controls $(n=821)$ reported at T3 of the longitudinal study ${ }^{\mathrm{a}}$

\begin{tabular}{|c|c|c|c|c|c|c|c|c|}
\hline & \multicolumn{2}{|c|}{$\begin{array}{l}\text { Model } 1 \\
\text { Predisposing } \\
\text { factors only }\end{array}$} & \multicolumn{2}{|c|}{$\begin{array}{l}\text { Model } 2 \\
\text { Model } 1+ \\
\text { perpetuating } \\
\text { factors T-1 }\end{array}$} & \multicolumn{2}{|c|}{$\begin{array}{l}\text { Model } 3 \\
\text { Model } 2+ \\
\text { concurrent } \\
\text { perpetuating } \\
\text { factors }\end{array}$} & \multicolumn{2}{|c|}{$\begin{array}{l}\text { Model } 4 \\
\text { Model 3+ } \\
\text { interaction } \\
\text { terms }\end{array}$} \\
\hline & $\beta$ & $95 \% \mathrm{CI}$ & $\beta$ & $95 \% \mathrm{Cl}$ & $\beta$ & $95 \% \mathrm{CI}$ & $\beta$ & $95 \%$ CI \\
\hline Intercept & 1.4 & $0.8-2.2$ & 0.7 & $0.1-1.3$ & 0.6 & -0.02 to 1.3 & 0.6 & -0.1 to 1.2 \\
\hline Female & 0.8 & $0.4-1.3$ & 0.8 & $0.4-1.3$ & 0.9 & $0.4-1.3$ & 0.9 & $0.4-1.3$ \\
\hline Age & -0.01 & -0.02 to 0.06 & 0.01 & -0.003 to 0.02 & 0.01 & -0.001 to 0.02 & 0.01 & -0.001 to 0.02 \\
\hline Low educational level & 0.3 & -0.1 to 0.7 & -0.1 & -0.5 to 0.2 & -0.1 & -0.4 to 0.2 & -0.1 & -0.4 to 0.2 \\
\hline Unemployed & 1.5 & $1.1-2.0$ & 0.9 & $0.4-1.3$ & 0.6 & $0.3-0.9$ & 0.6 & $0.2-0.9$ \\
\hline Immigrant & 3.2 & $2.7-3.7$ & 1.7 & $1.0-2.3$ & 1.1 & $0.5-1.7$ & 1.1 & $0.4-1.7$ \\
\hline Smoker & 1.0 & $0.4-1.6$ & 0.5 & $0.02-1.1$ & 0.4 & -0.1 to 0.8 & 0.4 & -0.1 to 0.8 \\
\hline Survivor of fireworks disaster & 1.1 & $0.7-1.4$ & -0.1 & -0.4 to 0.3 & -0.1 & -0.4 to 0.2 & -0.4 & -0.5 to 0.4 \\
\hline Physical symptoms $\mathrm{T}-1^{\mathrm{b}}$ & & & 2.9 & $2.5-3.4$ & 2.6 & $2.1-3.0$ & 3.1 & $2.4-3.7$ \\
\hline Feelings of depression $\mathrm{T}-1$ & & & 0.9 & $0.3-1.5$ & 0.3 & -0.2 to 0.8 & 0.3 & -0.3 to 0.8 \\
\hline Feelings of anxiety $\mathrm{T}-1$ & & & 1.5 & $0.9-2.1$ & 0.7 & $0.1-1.4$ & -0.03 & -1.0 to 1.0 \\
\hline Feelings of hostility $\mathrm{T}-1$ & & & 0.6 & $0.1-1.2$ & 0.2 & -0.3 to 0.7 & 0.5 & -0.2 to 1.2 \\
\hline Sleeping problems $\mathrm{T}-1$ & & & 0.7 & $0.3-1.0$ & 0.02 & -0.5 to 0.5$)$ & 0.4 & -0.5 to 1.2 \\
\hline $\begin{array}{l}\text { Feelings of depression } \\
\text { (concurrent) }\end{array}$ & & & & & 1.4 & $0.8-2.0$ & 1.4 & $0.8-2.0$ \\
\hline Feelings of anxiety (concurrent) & & & & & 1.1 & $0.6-1.5$ & 1.1 & $0.6-1.6$ \\
\hline Feelings of hostility (concurrent) & & & & & 0.5 & -0.002 to 1.0 & 0.5 & -0.003 to 1.0 \\
\hline Sleeping problems (concurrent) & & & & & 1.6 & $1.1-2.2$ & 1.0 & $0.3-1.7$ \\
\hline Survivor $\times$ physical symptoms $\mathrm{T}-1$ & & & & & & & -0.7 & -1.5 to 0.1 \\
\hline Survivor $\times$ feelings of anxiety $\mathrm{T}-1$ & & & & & & & 1.0 & -0.01 to 2.0 \\
\hline Survivor $\times$ feelings of hostility $\mathrm{T}-1$ & & & & & & & -0.5 & -1.5 to 0.5 \\
\hline Survivor $\times$ sleeping problems T-1 & & & & & & & -0.4 & -1.4 to 0.5 \\
\hline $\begin{array}{l}\text { Survivor } \times \text { sleeping problems } \\
(\text { concurrent) }\end{array}$ & & & & & & & 0.8 & $0.1-1.6$ \\
\hline
\end{tabular}

\footnotetext{
CI, Confidence interval.

a The regression coefficient $(\beta)$ is adjusted for chronic diseases and represents increase or decrease in symptoms on the 21-item symptom scale for survivors with that characteristic. Symptoms are: listlessness, fatigue, forgetfulness, ringing in the ears, pain in the chest and the region of the heart, lump in the throat, stomach ache, pain in the bones and muscles, nausea, dizziness, pain in the neck and shoulders, cold fingers, hand and feet, excessive sweating, pain in the back, headache, deafness, tight feeling in the chest, tingling in arms and chest, poor vision, shortness of breath, fainting.

b 13-item symptom scale (VOEG-13).
}

\section{REFERENCES}

Aaronson NK, Muller M, Cohen PD, Essink-Bot ML, Fekkes M, Sanderman R, Sprangers MA, te Velde A, Verrips E (1998). Translation, validation, and norming of the Dutch language version of the SF-36 health survey in community and chronic disease populations. Clinical Epidemiology 51, 1055-1068.

Aggarwal VR, McBeth J, Zakrzewska JM, Lunt M, Macfarlane GJ (2006). The epidemiology of chronic syndromes that are frequently unexplained: do they have common associated factors? International Journal of Epidemiology 35, 468-476.

Arrindell WA, Ettema JHM (1986). SCL-90: Manual for a Multidimensional Psychopathology Indicator [in Dutch]. Swets \& Zeitlinger : Lisse, The Netherlands.

Candy B, Chalder T, Cleare AJ, Peakman A, Skowera A, Wessely S, Weinman J, Zuckerman M, Hotopf M (2003).

Predictors of fatigue following the onset of infectious mononucleosis. Psychological Medicine 33, 847-855.

Derogatis LR, Lipman RS, Covi L (1973). SCL-90: an outpatient psychiatric rating scale preliminary report. Psychopharmacology Bulletin 9, 13-28.

Donker GA, Yzermans CJ, Spreeuwenberg P, van der Zee J (2002). Symptom attribution after a plan crash : comparison between self-reported symptoms and GP record. British Journal of General Practice 52, 917-922. 
Berg, B. van den, Grievink, L., Velden, P.G. van der, Yzermans, C.J., Stellato, R.K., Lebret, E., Brunekreef, B.

Risk factors for physical symptoms after a disaster: a longitudinal study.

Psychological Medicine: 2008, 38(4), 499-510

Engel CC (2003). Somatization and multiple idiopathic physical symptoms : relationship to traumatic events and posttraumatic stress disorder. In Trauma and Health : Physical Health Consequences of Exposure to Extreme Stress (ed. P. P. Schnurr and B. L. Green), pp. 191-215. American Psychological Association: Washington, DC.

Escobar JI, Canino G, Rubio-Stipec M, Bravo M (1992). Somatic symptoms alter a natural disaster : a prospective study. American Journal of Psychiatry 149, 965-967.

Escobar JI, Hoyos-Nervi C, Gara H (2002). Medically unexplained physical symptoms in medical practice : a psychiatric perspective. Environmental Health Perspectives 110, 631636.

Feder A, Olfson M, Gameroff M, Fuentes M, Shea S, Lantigua RA, Weissman MM (2001). Medically unexplained symptoms in urban general medicine practice. Psychosomatics 43 , 261-268.

Gray GC, Reed RJ, Kaiser KS, Smith TC, Gastanaga VM (2002). Self-reported symptoms and medical conditions among 11868 Gulf War-era veterans : The Seabee Health Study. American Journal of Epidemiology 155, 1033-1044.

Green LA, Fryer GE, Yawn BP, Lanier D, Dovey SM (2001). The ecology of medical care revisited. New England Journal of Medicine 344, 2021-2025.

Grievink L, van der Velden PG, Stellato RK, Dusseldorp A, Gersons BPR, Kleber RJ, Lebret E (2007). A longitudinal comparative study of the physical and mental health problems of affected residents of the firework disaster Enschede, the Netherlands. Public Health 121, 367-374.

Grievink L, van der Velden PG, Yzermans CJ, Roorda J, Stellato RK (2006). The importance of estimating selection bias on prevalence estimates shortly after a disaster. Annals of Epidemiology 16, 782-788.

Hassett AL, Sigal LH (2002). Unforeseen consequences of terrorism : medically unexplained symptoms in time of fear. Archives of Internal Medicine 162, 1809-1813.

Hatcher S, House A (2003). Life events, difficulties and dilemmas in the onset of chronic fatigue syndrome: a case-control study. Psychological Medicine 33, 1185-1192

Haug TT, Mykletun A, Dahl AA (2004). The association between anxiety, depression and somatic symptoms in a large population: the HUNT-II study. Psychosomatic Medicine 66, 845-851.

Hiller W, Rief W, Brahler E (2006). Somatization in the population: from mild bodily misperceptions to disabling symptoms. Social Psychiatry and Psychiatric Epidemiology 41, 704-712.

Horowitz MJ, Wilner N, Alvarez W (1979). The impact of event scale : a measure of subjective stress. Psychosomatic Medicine 41, 209-218.

Hotopf M, David A, Hull L, Nikalaou V, Unwin C, Wessely S (2004). Risk factors for continued illness among Gulf War veterans : a cohort study. Psychological Medicine 34, 747-754.

Hotopf M, Mayou R, Wadsworth M, Wessely S (1999). Childhood risk factors for adults with medically unexplained symptoms : results from a national birth cohort study. American Journal of Psychiatry 156, 1796-1800.

Katon WJ, Walker EA (1998). Medically unexplained symptoms in primary care. Journal of Clinical Psychiatry 59, 15-21.

Kroenke K, Price RK (1993). Symptoms in the community : prevalence, classification and psychiatric comorbidity. Archives of Internal Medicine 153, 2474-2480.

Lazzeroni LG, Schenker N, Taylor JMG (1990). Robustness of multiple imputation techniques to model misspecification. Proceedings of the Survey Research Methods, pp. 260-265.

Marmar CR, Weiss DS, Metzler TJ (1997). The peritraumatic dissociation experiences questionnaire. In Assessing Psychological Trauma and PTSD (ed. J. P. Wilson and T. M. Keane), pp. 412-428. Guilford Press : New York.

Mayou, R, Farmer, A. (2002). Functional somatic symptoms and syndromes. British Medical Journal 325, 265-268.

Meijman TF, de Vries-Griever AHG, de Vries G, Kampman R (1985). The Construction and Evaluation of a One-dimensional Scale Measuring Subjective Sleep Quality. State University Groningen: Groningen. 
Berg, B. van den, Grievink, L., Velden, P.G. van der, Yzermans, C.J., Stellato, R.K., Lebret, E., Brunekreef, B.

Risk factors for physical symptoms after a disaster: a longitudinal study.

Psychological Medicine: 2008, 38(4), 499-510

Mooren T, Kleber RJ (2001). The Impact of War: Studies on the Psychological Consequences of War and Migration. Eburon: Delft.

Norris RL, Maguen S, Litz BT, Adler AB, Britt TW (2005). Physical health symptoms in peacekeepers : has the role of deployment stress been overrated? Stress, Trauma, and Crisis 8, 1-15.

Petersen I, Thomas JM, Hamilton WT, White PD (2006). Risk and predictors of fatigue after infectious mononucleosis in a large primary-care cohort. Quarterly Journal of Medicine 99, 49-55.

Roorda J, Van Stiphout WA, Huijsman-Rubingh RRR (2004). Post-disaster health effects : strategies for investigation and data collection. Experiences from the Enschede firework disaster. Journal of Epidemiology and Community Health 58, 982-987.

Rubin DB (1987). Multiple Imputation for Nonresponse in Surveys. John Wiley \& Sons: New York.

Schafer JL, Graham JW (2002). Missing data: our view of the state of the art. Psychological Methods 7, 147-177.

Scheier MF, Carver CS, Bridges MW (1994). Distinguishing optimism from neuroticism and trait anxiety, self-mastery and self-esteem: a re-evaluation of the life orientation test. Journal of Personality and Social Psychology 67, 1063-1078.

Schnurr PP, Green BL (2003). Understanding relationships among trauma, posttraumatic stress disorder, and health outcomes. In Trauma and Health : Physical Health Consequences of Exposure to Extreme Stress (ed. P. P. Schnurr and B. L. Green), pp. 247-275. American Psychological Association : Washington, DC.

Singer JD, Willett JB (2003). Applied Longitudinal Data Analysis. Modeling Change and Event Occurrence. Oxford University Press: New York.

Terheggen MA, Stroebe MS, Kleber RJ (2001). Western conceptualizations and Eastern experience: a cross-cultural study of traumatic stress reactions among Tibetan refugees in India. Journal of Traumatic Stress 14, 391-403.

Thomas HV, Stimpson NJ, Weightman AL, Dustan F, Lewis G (2006). Systematic review of multi-symptom conditions in Gulf War veterans. Psychological Medicine 36, 735-747.

Unwin C, Blatchley N, Coker W, Ferry S, Hotopf M, Hull L, Ismail K, Palmer I, David A, Wessely S (1999). Health of UK servicemen who served in the Persian Gulf War. Lancet 353, 169-178.

Van den Berg B, Grievink L, Stellato RK, Yzermans CJ, Lebret E (2005b). Symptoms and related functioning in a traumatized community. Archives of Internal Medicine 165, 24022407.

Van den Berg B, Grievink L, Yzermans CJ, Lebret E (2005a). Medically unexplained physical symptoms in the aftermath of disasters. Epidemiologic Reviews 27, 92-106.

Van den Berg B, van der Velden P, Stellato R, Grievink L (2007). Selective attrition and bias in a longitudinal health survey among survivors of a disaster. BMC Medical Research Methodology 7, 8.

Van der Ploeg E, Mooren TT, Kleber RJ, van der Velden PG, Brom D (2004). Construct validation of the Dutch version of the impact of event scale. Psychological Assessment 16, 16-26.

Van der Ploeg HM, Defares PB, Spielberger CK (1982). Manual of the State Anxiety Inventory [in Dutch]. Swets \& Zeitlinger : Lisse.

Van der Velden PG, Kleber RJ, Christiaanse B, Gersons BP, Marcelissen FG, Drogendijk AN, Grievink L, Olff M, Meewisse ML (2006). The independent predictive value of peritraumatic dissociation of post-disaster intrusions, avoidance reactions and PTSD symptom severity : a four-year prospective study. Journal of Traumatic Stress 19, 493506.

Van der Zee KI, Sanderman R (1993). Measuring General Health with the RAND-36: A Manual [in Dutch]. Noordelijk Centrum voor Gezondheidsvraagstukken: Groningen.

Van Kamp, I, van der Velden, PG, Stellato, RK, Roorda, J, van Loon, J, Kleber, RJ, Gersons, BB, Lebret, E. (2006). Physical and mental health shortly after a disaster : first results from the Enschede firework disaster study. European Journal of Public Health 16, 252-258.

Van Sonderen E (1993). Measuring Social Support with the Social Support Questionnaire Interaction (SSL-I) and the Social Support Questionnaire - Discrepancies (SSL-D) [in Dutch]. Noordelijke Centrum voor Gezondheidsvraagstukken: Groningen. 
Berg, B. van den, Grievink, L., Velden, P.G. van der, Yzermans, C.J., Stellato, R.K., Lebret, E., Brunekreef, B.

Risk factors for physical symptoms after a disaster: a longitudinal study.

Psychological Medicine: 2008, 38(4), 499-510

Van Sonsbeek LJA (1990). The VOEG: A List of Subjective Health Complaints (Statistical Reports M37) [in Dutch]. Dutch Office for Statistics : Heerlen/The Hague.

Wolfe J, Proctor SP, Davis JD, Borgos MS, Friedman MJ (1998). Health symptoms reported by Persian Gulf War veterans two years after return. American Journal of Industrial Medicine 33, 104-113.

Yzermans CJ, Donker GA, Kerssens JJ, Dirkzwager AJ, Soeteman RJ, ten Veen PM (2005). Health problems of victims before and after disaster : a longitudinal study in general practice. International Journal of Epidemiology 34, 820-826. 